American Journal of Pharmaceutical Education 2019; 83 (7) Article 7136.

\title{
RESEARCH
}

\section{An Assessment of Pharmacy Students' Psychological Attachment to Smartphones at Two Colleges of Pharmacy}

\author{
Jeff Cain, EdD, ${ }^{a}$ Daniel R. Malcom, PharmD ${ }^{\mathrm{b}, \mathrm{c}}$ \\ ${ }^{a}$ University of Kentucky College of Pharmacy, Lexington, Kentucky \\ ${ }^{\mathrm{b}}$ Sullivan University College of Pharmacy and Health Sciences, Louisville, Kentucky \\ ${ }^{\mathrm{c}}$ Associate Editor, American Journal of Pharmaceutical Education, Arlington, Virginia \\ Submitted April 23, 2018; accepted June 25, 2018; published September 2019.
}

Objective. To determine the prevalence of nomophobia, the discomfort or anxiety experienced from being without a cellphone, among student pharmacists.

Methods. A validated nomophobia questionnaire (NMP-Q) was administered to two groups of student pharmacists at two different Doctor of Pharmacy programs $(\mathrm{N}=192)$. Demographic and other information was collected including identified gender, year of birth, type of smartphone, and use of messaging services. Scores on the NMP-Q were used to classify respondents as absent of nomophobia $(<20)$, having mild nomophobia (21-59), having moderate nomophobia (60-99), or having severe nomophobia ( $>100$ out of a maximum score of 140$)$.

Results. Of 224 eligible students, 192 (85.7\%) responded to the survey. Mean nomophobia scores were statistically similar between programs. Most students' scores were within the moderate nomophobia range $(56.8 \%)$, while $24.5 \%$ were in the mild range and $18.2 \%$ were in the severe range. Score classifications were similar between schools. Overall, the data showed good internal consistency, with a Cronbach's alpha of .95 for the combined group.

Conclusion. Nomophobia is a relatively new psychological phenomenon, and little is known about its potential implications. The student pharmacists in our study all had NMP-Q scores consistent with some degree of nomophobia. Educators must continue to study smartphone use and help student pharmacists maximize the benefits of smartphones while avoiding the potential negative psychological consequences associated with their use.

Keywords: smartphones, nomophobia, mental health, internet dependence, anxiety

\section{INTRODUCTION}

An estimated $96 \%$ of Americans own a mobile phone, and $81 \%$ own a smartphone, according to 2019 data. ${ }^{1}$ Smartphones have become a tool for much more than just phone calls and messaging. A large percentage of Americans use them for online shopping, receiving news alerts, monitoring health information, doing work-related tasks, getting driving directions, and a host of other activities via mobile apps. ${ }^{1}$ Smartphone usage is prominent in the health care environment and offers a number of benefits, including accessing medical references, record keeping, billing, among other uses. $^{2}$ Because of the many conveniences smartphones afford, they have become integrated into our everyday lives and, for many, have become seemingly indispensable. In a

Corresponding Author: Jeff Cain, University of Kentucky College of Pharmacy, 114M Lee T. Todd, Jr. Building, 789 S. Limestone Dr., Lexington, KY 40536-0596. Tel: 859-2574429. E-mail: jeff.cain@uky.edu
2015 Pew Interest Research study, 46\% of surveyed smartphone owners indicated they "could not live without it."3

Despite all the conveniences and affordances of digital and mobile communications, there is growing concern regarding the potential negative effects these devices may have on mental health. ${ }^{4}$ Reports of research linking excessive use of smartphones and associated social media apps with stress, anxiety, depression, and other psychological ailments are becoming increasingly common. ${ }^{5-9}$ While college instructors have long lamented that many students' are unwilling to dispense with smartphone use during class or other academic activities, investigators and digital technology leaders have only recently begun to research and discuss the potentially dependence-inducing nature of the devices. ${ }^{10}$ Many technology inventors and developers responsible for the design of digital phone and application features have begun efforts to combat dependenceinducing technologies after confessing that the devices and apps were designed to use psychological "hooks" such 


\section{American Journal of Pharmaceutical Education 2019; 83 (7) Article 7136.}

as variable rewards and color to capture and maintain users' attention. ${ }^{11,12}$ Even college students have recognized the potential problems with smartphone overuse and have begun to organize grassroots efforts to address the potential psychological impact of digital devices. ${ }^{13}$

If smartphones have the potential for psychological dependence, as the research suggests, it is incumbent upon educators to consider and address these issues in relation to student success and well-being. One of the first steps in fully comprehending the issues is to determine the actual extent of the problem of psychological dependence on technologies among students. Studies examining facets of mobile phone and internet dependence have indicated an emerging trend in problematic attachment to digital phones, particularly among female and younger users. ${ }^{14}$ One area of research that offers insight into these issues is measurement of a construct called "nomophobia," a portmanteau of the words no, mobile, phone, and phobia. This relatively new construct is a situational phobia and refers to the discomfort or anxiety experienced by an individual because a mobile digital device is not available. ${ }^{15}$ It encompasses the psychological need for continuous digital connection and the compulsion to constantly check the device for "updates" in the form of texts, social media notifications, etc. Some psychologists have proposed that nomophobia be included in the Diagnostic and Statistical Manual of Mental Disorders. ${ }^{16}$ Currently, the most wellstudied and validated method of assessing nomophobia is the nomophobia questionnaire (NMP-Q). ${ }^{17}$ The NMP-Q is a validated 20 -item assessment on which respondents rate their level of agreement with each item using a seven-point Likert-type scale. The resulting total score is then used to rank the respondent's level of nomophobia from absent to severe.

Because of the increasing use of smartphones as tools for health professions students and trainees, determining whether there are deleterious effects related to that use is important. ${ }^{18}$ A search for nomophobia research at the time of this writing in early 2018 revealed only nine studies with health professions students or trainees as subjects. All of those studies were in settings outside of the United States (India, Saudi Arabia, and Indonesia). Seven of the nine studies involved medical students ${ }^{19-24}$ or residents ${ }^{25}$ and the other two involved dental students ${ }^{26}$ and undergraduate health professions students. ${ }^{27}$ This study, which measured nomophobia levels of student pharmacists, is believed to be the first such study of health professions students or trainees in the United States and will provide foundational research on nomophobia in this population.

\section{METHODS}

A 29-item survey instrument was developed on Qualtrics (Qualtrics, LLC, Provo, UT) in March 2018. The survey consisted of the 20-question NMP-Q (used without modification), ${ }^{17}$ in addition to three demographic questions, five background questions pertaining to smartphone usage, and one item requesting informed consent to use the survey results for research purposes. The NMP-Q is divided into four "factors," each associated with a different facet of the psychology around nomophobia: not being able to communicate, losing connectedness, not being able to access information, and giving up convenience. Each item (consisting of an affirmative statement) is evaluated by the respondent using a Likert-type scale ranging from $1=$ strongly disagree to $7=$ strongly agree, with $4=$ neither agree nor disagree. The numerical ratings for all 20 items are combined to make the overall nomophobia score, which has a maximum value of 140 . The score is then converted to a nomophobia classification based on validated cutoffs: absent of nomophobia $(<20)$, mild (21-59), moderate (60-99), and severe $(>100) .{ }^{17}$ Full text of the items in the NMP-Q is available in Tables 3 and 5.

The complete online instrument was pre-tested using a convenience sample of three student pharmacists in their final year of the Doctor of Pharmacy (PharmD) program for face validity and comprehensibility of the demographic and background questions. Each student completed the questionnaire and was then asked by an investigator to explain what she or he thought the questionnaire asked and if any question was confusing. Based on pre-testing, two background questions regarding number of messages sent and received daily were revised. The phrase "text messages" was replaced with "messages (ie, text, Facebook messenger, GroupMe, SnapChat, etc)" to encompass the full range of messaging systems that students potentially use. Testing concluded after the second and third students reported full comprehension of the questions with no suggested revisions.

Participants in this study were student pharmacists in their final didactic year at the University of Kentucky College of Pharmacy (UKCOP) and Sullivan University College of Pharmacy and Health Sciences (SU COPHS) PharmD programs, both located in Kentucky, in the midwestern United States. Participants from UKCOP (a public, four-year program) were recruited from a third professional-year course. All students in the course completed the survey on Qualtrics as part of their required course activities and were given the option to include their results in this study. No incentives (eg, extra credit, prizes) were provided to opt in. The link to the questionnaire was provided in the course's Canvas (Instructure, Salt Lake City, Utah) learning management shell.

Participants from SU COPHS (a private, three-year accelerated program) were recruited from a second professional-year course. Like UKCOP, all students in the 


\section{American Journal of Pharmaceutical Education 2019; 83 (7) Article 7136.}

course completed the survey as part of required course activities and were provided an option to include their results in this study on an opt-in basis. The SU COPHS participants used the same survey link and platform as UKCOP students, which was emailed rather than posted into a course learning management system. The study was approved as exempt by both schools' institutional review boards.

Results were downloaded from Qualtrics into a spreadsheet for further analysis. Statistics were performed on the data set using Microsoft Excel 2016 (Redmond, WA) and SPSS version 23 (IBM Corp. Armonk, NY). First, baseline demographic data were compared between schools. Mean nomophobia scores were compared between schools using an unpaired $t$ test. Discrete data were compared using chi-square test or Fisher's exact test where appropriate. For the individual factor analyses, one-way analysis of variance (ANOVA) was employed. A significance level of .05 was established a priori for all statistical tests. Multiple reliability analyses were also conducted on the survey data, including Cronbach's alpha, corrected item-total correlation, and Cronbach's alpha if item deleted. Cronbach's alpha is a measurement of internal consistency of a data set. ${ }^{28}$

\section{RESULTS}

Of 224 students eligible to participate, 192 responded to the survey and consented to have their results included for analysis in the study, resulting in an overall response rate of $85.7 \%$. Seventy-three of the participants were from SU COPHS (out of 83, 88\% response rate), and
119 were from UKCOP (out of 141, 84\% response rate). Sixty-eight (35.4\%) were male, and 124 (64.6\%) were female. This closely mirrors the average ratio of male to female graduates as reported for PharmD programs nationally, which was $38.7 \%$ male and $61.3 \%$ female according to the most recent data available (2015-2016 academic year) available. ${ }^{29}$ Full demographic results are shown in Table 1. Most of the students $(84.9 \%)$ were born between 1977 and 1994. All (100\%) students reported owning a smartphone, with the majority $(81.3 \%)$ owning an Apple iPhone. There were no significant differences between the two cohorts (SU COPHS and UKCOP) at baseline $(p>.05)$.

Overall mean nomophobia scores were statistically similar between programs $(p=.64)$. As shown in Table 2, most students' scores fell within the "moderate" nomophobia range $(56.8 \%)$, with $24.5 \%$ falling into the "mild" range and $18.2 \%$ being classified as "severe." One student $(0.5 \%)$ reported a score classified as "absent" of nomophobia. Score classifications were similar between schools $(p=.38)$.

Table 3 displays full results for each item on the NMP-Q with reliability data. The commonly accepted minimum value for internal consistency is .7, although this can vary by type of assessment. ${ }^{30}$ Overall, the data in our study showed good internal consistency, with a Cronbach's alpha for the combined group of .95. The Cronbach's alpha for the SU COPHS data was .96, and the Cronbach's alpha for the UKCOP data was .93, both of which were above the acceptable value of .7. Each of the four factors of the NMP-Q also showed good internal consistency $\left(.94, .84, .84, .81\right.$, respectively). ${ }^{30-32}$

Table 1. Demographics of Respondents to a Survey to Determine Student Pharmacists' Psychological Attachment to Smartphones

\begin{tabular}{|c|c|c|c|c|}
\hline & $\begin{array}{l}\text { All Students } \\
\mathrm{N}=192(\%)\end{array}$ & $\begin{array}{c}\text { SU COPHS } \\
n=73(\%)\end{array}$ & $\begin{array}{c}\text { UKCOP } \\
n=119(\%)\end{array}$ & $p$ value $^{\mathrm{a}}$ \\
\hline \multicolumn{5}{|l|}{ Gender } \\
\hline Female & $124(64.6)$ & $52(71.2)$ & $72(60.5)$ & \\
\hline \multicolumn{5}{|l|}{ Year born } \\
\hline Prior to 1966 & $0(0)$ & $0(0)$ & $0(0)$ & .38 \\
\hline After 1994 & $27(14.1)$ & $13(17.8)$ & 14 (11.8) & \\
\hline \multicolumn{5}{|l|}{ Smartphone owned } \\
\hline No smartphone & $0(0)$ & $0(0)$ & $0(0)$ & .25 \\
\hline Samsung & $25(13)$ & $15(20.5)$ & $10(8.4)$ & \\
\hline Apple (iPhone) & $156(81.3)$ & $56(76.7)$ & $100(84)$ & \\
\hline
\end{tabular}

Abbreviations: SU COPHS=Sullivan University College of Pharmacy and Health Sciences; UKCOP=University of Kentucky College of Pharmacy

${ }^{a}$ Chi-square test or Fisher exact test between programs; $p<.05$ indicates significance 


\section{American Journal of Pharmaceutical Education 2019; 83 (7) Article 7136.}

Table 2. Results on the Nomophobia Questionnaire Administered to Determine Student Pharmacists' Psychological Attachment to Smartphones

\begin{tabular}{lcccc}
\hline & $\begin{array}{c}\text { All students } \\
\mathbf{N = 1 9 2}(\mathbf{\%})\end{array}$ & $\begin{array}{c}\text { SU COPHS } \\
\mathbf{n = 7 3}(\mathbf{\%})\end{array}$ & $\begin{array}{c}\text { UKCOP } \\
\mathbf{n = 1 1 9}(\%)\end{array}$ & $\boldsymbol{p ~ v a l u e ~}^{\mathbf{b}}$ \\
\hline Nomophobia classification $^{\mathrm{a}}$ & $1(0.5)$ & $1(1.4)$ & $0(0)$ & .38 \\
$\quad$ Absent & $47(24.5)$ & $18(24.7)$ & $29(24.4)$ & \\
Mild & $109(56.8)$ & $38(52.1)$ & $19(59.7)$ & \\
Moderate & $35(18.2)$ & $16(21.9)$ & $19(16)$ & \\
Severe & & & & \\
\hline
\end{tabular}

Abbreviations: SU COPHS=Sullivan University College of Pharmacy and Health Sciences; UKCOP=University of Kentucky College of

Pharmacy

${ }^{\text {a }}$ Score threshold for classification: Absent $(<20)$, Mild (21-59), Moderate (60-99), Severe $(>100)$

${ }^{\mathrm{b}}$ Chi-square test or Fisher exact test between programs; $p<.05$ indicates significance

As no significant differences were found, the data from the two institutions were combined for further analyses. Full subgroup analyses are shown in Tables 4 and 5. Among all students, significantly more female students reported scores qualifying as severe nomophobia $(>100)$ compared to male students ( 24 female students vs 8 male students; $p=.02$ ). Additionally, iPhone users were more likely to report scores classified as moderate or severe compared to non-iPhone users $(p<.01)$. Although four age groups were used in the survey, groups were collapsed into two groups for analysis because few students were born prior to 1966 or between 1966 and 1976. The final two age groups analyzed were students born in 1994 or prior and those born after 1994. Those born in 1994 or prior had statistically similar nomophobia score classifications as those born after $1994(p=.14)$.

The effect of gender on nomophobia scores was also assessed in this study. Mean score for male students was $70.8(\mathrm{SD}=23.4)$, while the mean score for female students was significantly higher at $79.5(\mathrm{SD}=24.7 ; p=.02)$. Table 5 shows a detailed breakdown of the effect of gender on individual items and factor scores on the NMP-Q. Overall, the mean (SD) score (on a scale of 1 to 7) of all items was higher among female students $(\mathrm{M}=4, \mathrm{SD}=1.2)$ than among male students $(\mathrm{M}=3.54, \mathrm{SD}=1.2 ; p=.02)$. The item, "I would be annoyed if I could not look up information on my smartphone when I wanted to do so" received the highest mean score (5.5 out of 7) for both genders, with no significant difference $(p=.23)$ between the groups. Among the four factors of the NMP-Q, only factor I (not being able to communicate) and factor IV (giving up convenience) contained individual items that showed significant differences by gender. The greatest difference in mean scores (1.6) between genders was found in responses to the item, "If I could not use my smartphone, I would be afraid of getting stranded somewhere," with a mean score of 4.9 for female students vs 3.3 for male students, which was significant $(p<.01)$.

\section{DISCUSSION}

Accreditation Council for Pharmacy Education (ACPE) standards reflect an increased emphasis on student well-being. ${ }^{33}$ Additionally, there is growing concern among educators and researchers that digital technologies such as smartphones are dependence-inducing in nature and thus may contribute negatively to student academic success and well-being. This study sought to fill a gap in the literature by determining nomophobia levels of student pharmacists at two colleges of pharmacy in the United States through administration and analysis of the NMP-Q. Results of this study should help inform future research regarding the relationship of smartphones to students' academic and personal well-being. Perhaps more importantly, it provides pharmacy educators with data to hold more informed discussions regarding how we view the roles of, policies toward, and positive and negative features of smartphones and other digital devices in health professions education.

The results of this study are similar to those from international studies of medical and dental students that used modified versions of the NMP-Q or had elements of the NMP-Q combined with other surveys. ${ }^{19-27}$ Varying, but significant degrees of nomophobia prevalence were found among the participants. The percentage of health professions students with severe nomophobia ranged from $7.5 \%$ to $22.2 \%$ in those studies, ${ }^{20-22,27}$ while the percentage of student pharmacists in our study with severe nomophobia was $18.2 \%$. Farooqui and colleagues' cross-sectional study of 145 medical students in India revealed that $22.1 \%$ and $60 \%$ had severe or moderate nomophobia, respectively, which closely mirrors our results of $18.2 \%$ and $56.8 \%$ with severe or moderate nomophobia, respectively. ${ }^{21} \mathrm{Be}-$ cause of differences in reporting by previous researchers, directly comparing their study results to ours was challenging. However, all of those studies found a high prevalence of nomophobia, and nearly 


\section{American Journal of Pharmaceutical Education 2019; 83 (7) Article 7136.}

Table 3. Item-level Data for the Nomophobia Questionnaire (NMP-Q) Administered to Determine Student Pharmacists' Psychological Attachment to Smartphones $(\mathrm{N}=192)^{\mathrm{a}}$

\begin{tabular}{|c|c|c|c|c|}
\hline & M (SD) & $\begin{array}{c}\text { Corrected } \\
\text { item-total } \\
\text { correlation } \\
\end{array}$ & $\begin{array}{c}\text { Cronbach's } \\
\text { alpha if item } \\
\text { deleted }\end{array}$ & $\begin{array}{c}\text { Cronbach's } \\
\text { alpha }\end{array}$ \\
\hline Factor I: Not being able to communicate (6 items) & $4.1(1.8)$ & & & .94 \\
\hline \multicolumn{5}{|l|}{ If I did not have my smartphone with me, } \\
\hline $\begin{array}{l}\text { I would feel anxious because I could not instantly } \\
\text { communicate with my family and/or friends. }\end{array}$ & $4(1.9)$ & .79 & .94 & \\
\hline $\begin{array}{l}\text { I would be worried because my family and/or friends } \\
\text { could not reach me. }\end{array}$ & $4.6(1.8)$ & .65 & .94 & \\
\hline $\begin{array}{l}\text { I would feel nervous because I would not be able to } \\
\text { receive text messages and calls. }\end{array}$ & $4(1.9)$ & .83 & .94 & \\
\hline $\begin{array}{l}\text { I would be anxious because I could not keep in touch } \\
\text { with my family and/or friends. }\end{array}$ & $4.1(1.8)$ & .78 & .94 & \\
\hline $\begin{array}{l}\text { I would be nervous because I could not know if someone } \\
\text { had tried to get a hold of me. }\end{array}$ & $4.2(1.8)$ & .75 & .94 & \\
\hline $\begin{array}{l}\text { I would feel anxious because my constant connection to } \\
\text { my family and friends would be broken. }\end{array}$ & $3.5(1.7)$ & .75 & .94 & \\
\hline Factor II: Losing connectedness (5 items) & $2.8(1.8)$ & & & .84 \\
\hline \multicolumn{5}{|l|}{ If I did not have my smartphone with me, } \\
\hline $\begin{array}{l}\text { I would be nervous because I would be disconnected } \\
\text { from my online identity. }\end{array}$ & $2(1.2)$ & .63 & .94 & \\
\hline $\begin{array}{l}\text { I would be uncomfortable because I could not stay up-to- } \\
\text { date with social media and online networks. }\end{array}$ & $2.8(1.7)$ & .68 & .94 & \\
\hline $\begin{array}{l}\text { I would feel awkward because I could not check my } \\
\text { notifications for updates from my connections and } \\
\text { online networks. }\end{array}$ & $2.8(1.8)$ & .63 & .94 & \\
\hline $\begin{array}{l}\text { I would feel anxious because I could not check my email } \\
\text { messages. }\end{array}$ & $3.4(1.9)$ & .53 & .95 & \\
\hline I would feel weird because I would not know what to do. & $3.1(1.9)$ & .57 & .95 & \\
\hline Factor III: Not being able to access information (4 items) & $4.7(1.8)$ & & & .84 \\
\hline $\begin{array}{l}\text { I would feel uncomfortable without constant access to } \\
\text { information through my smartphone. }\end{array}$ & $4.6(1.7)$ & .64 & .94 & \\
\hline $\begin{array}{l}\text { I would be annoyed if I could not look information up } \\
\text { on my smartphone when I wanted to do so. }\end{array}$ & $5.5(1.5)$ & .55 & .95 & \\
\hline $\begin{array}{l}\text { Being unable to get the news (eg, happenings, weather, etc.) } \\
\text { on my smartphone would make me nervous. }\end{array}$ & $3.5(1.8)$ & .66 & .94 & \\
\hline $\begin{array}{l}\text { I would be annoyed if I could not use my smartphone and/or } \\
\text { its capabilities when I wanted to do so. }\end{array}$ & $5.2(1.5)$ & .63 & .94 & \\
\hline Factor IV: Giving up convenience (5 items) & $3.8(1.9)$ & & & .81 \\
\hline Running out of battery in my smartphone would scare me. & $3.6(1.9)$ & .65 & .94 & \\
\hline $\begin{array}{l}\text { If I were to run out of credits or hit my monthly data limit, } \\
\text { I would panic. }\end{array}$ & $3(1.8)$ & .71 & .94 & \\
\hline $\begin{array}{l}\text { If I did not have a data signal or could not connect to Wi-Fi, } \\
\text { then I would constantly check to see if I had a signal or } \\
\text { could find a Wi-Fi network. }\end{array}$ & $3.3(1.9)$ & .67 & .94 & \\
\hline $\begin{array}{l}\text { If I could not use my smartphone, I would be afraid of } \\
\text { getting stranded somewhere. }\end{array}$ & $4.3(1.9)$ & .55 & .95 & \\
\hline $\begin{array}{l}\text { If I could not check my smartphone for a while, I would } \\
\text { feel a desire to check it. }\end{array}$ & $4.9(1.6)$ & .68 & .94 & \\
\hline Overall Cronbach's alpha & & & & .95 \\
\hline
\end{tabular}

${ }^{a}$ The NMP-Q consists of Likert-type items including: $1=$ strongly disagree, $2=$ disagree, $3=$ somewhat disagree, $4=$ neither agree nor disagree, $5=$ somewhat agree, $6=$ agree, and $7=$ strongly agree 


\section{American Journal of Pharmaceutical Education 2019; 83 (7) Article 7136.}

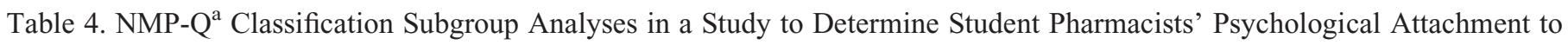
Smartphones $(\mathrm{N}=192)$

\begin{tabular}{|c|c|c|c|c|c|}
\hline & $\begin{array}{c}\text { Absent } \\
\text { n (\%) }\end{array}$ & $\begin{array}{l}\text { Mild } \\
\text { n (\%) }\end{array}$ & $\begin{array}{c}\text { Moderate } \\
\text { n (\%) }\end{array}$ & $\begin{array}{l}\text { Severe } \\
\text { n }(\%)\end{array}$ & $\begin{array}{c}p \\
\text { value }^{\mathrm{b}}\end{array}$ \\
\hline \multicolumn{6}{|l|}{ Gender } \\
\hline Male $(n=68)$ & $1(1.5)$ & $19(27.9)$ & $40(58.8)$ & $8(11.8)$ & .02 \\
\hline Female $(n=124)$ & $0(0)$ & $28(22.6)$ & $36(29)$ & $24(19.4)$ & \\
\hline \multicolumn{6}{|l|}{ Smartphone type } \\
\hline iPhone $(n=156)$ & $1(0.6)$ & $30(19.2)$ & $95(60.9)$ & $30(19.2)$ & .003 \\
\hline Non-iPhone $(n=36)$ & $0(0)$ & $17(47.2)$ & $17(47.2)$ & $2(5.6)$ & \\
\hline \multicolumn{6}{|l|}{ Year born } \\
\hline Before $1994(n=165)$ & $0(0)$ & $43(26.1)$ & $95(57.6)$ & $27(16.4)$ & .14 \\
\hline After $1994(n=27)$ & $1(3.7)$ & $4(14.8)$ & $17(63)$ & $5(18.5)$ & \\
\hline
\end{tabular}

${ }^{a}$ NMP-Q=Nomophobia Questionnaire

${ }^{\mathrm{b}}$ Chi-square test or Fisher exact test; $p<.05$ indicates significance

all $(99.5 \%)$ of the students in our study reported some degree of nomophobia.

In our study, gender had a significant impact on overall mean nomophobia scores, specific individual items in the survey, and classification of the levels of severity (absent, mild, moderate, or severe). This aligns with general findings in cellphone addiction research ${ }^{14}$ and adds to the body of nomophobia research indicating that female students are more likely to score higher on tests for nomophobia. Chandak and colleagues' study of medical residents showed that female residents overall were more nomophobic than male residents $(p=.02) .{ }^{25}$ Female medical students in the study by Dasgupta and colleagues also had a significantly higher prevalence of nomophobia (57.8\% for female students vs $34 \%$ for male students; $p<.01) .{ }^{19}$ Prasad and colleagues also showed a higher prevalence of nomophobia among female dental students surveyed $(28.7 \%$ for female students vs $20.7 \%$ for male students), though this did not reach significance $(p=.09) .{ }^{26}$ Despite female students generally being more nomophobic and more susceptible to other mobile phone dependencies, results are not consistent across the literature. Farooqui and colleagues did not find a significant difference between genders on classification of nomophobia as mild, moderate, or severe $(p=.69),{ }^{21}$ and Dixit and colleagues found a similar prevalence of nomophobia between genders (19\% of male students and $18 \%$ of female students). ${ }^{20}$ Further research on the effect of gender on smartphone and mobile phone dependence is needed.

In many ways, the results of this study were not unexpected. The current generation of college-age individuals have had cellphones and/or smartphones most of their life. Hence, their reliance on them for various aspects of their lives should be expected. The individual factor results in this study provide additional insight into this phenomenon. Factor III of the NMP-Q (ie, not being able to access information) had the highest mean (SD) score, 4.7 $(\mathrm{SD}=1.8)$. Two of the four items in factor III also had the highest mean scores overall. The items, "I would be annoyed if I could not look up information on my smartphone when I wanted to do so" and "I would be annoyed if I could not use my smartphone and/or its capabilities when I wanted to do so," had respective mean scores of $5.5(\mathrm{SD}=1.5)$ and $5.2(\mathrm{SD}=1.5)$. The results on these individual factors reflect the reports from Chandak and colleagues that also showed these individual items as among the highest four scores. ${ }^{25}$ This suggests that students indeed rely on their smartphones as a primary tool for information and other day-to-day functions. Our study lends credence to the idea suggested by Fjortoft and colleagues that students may prefer strategies of information access versus memorization and recall. ${ }^{18}$ The item, "If I could not check my smartphone for a while, I would feel a desire to check it," had the third highest mean (4.9, $\mathrm{SD}=1.6$ ), which touches upon the potential addictive nature of the device. This illustrates the "pull" that smartphones may have on students during class, study sessions, meetings, etc.

One of the primary concerns for educators regarding students who have a compulsive desire to monitor smartphones is the effect on academic performance. The literature is replete with studies indicating that smartphone use during class adversely affects students' grades and other indicators of academic success. ${ }^{34-36}$ Students have long succumbed to distractions in the classroom during periods of boredom, but anxiety that compels students to use their smartphones even when not bored presents another level of concern. A study by Cheever and colleagues showed that when heavy users of wireless mobile devices were restricted from using them, they felt significantly 


\section{American Journal of Pharmaceutical Education 2019; 83 (7) Article 7136.}

Table 5. Effect of Gender on Average Nomophobia Questionnaire (NMP-Q) Scores in a Study to Determine Student Pharmacists' Psychological Attachment to Smartphones $(\mathrm{N}=192)^{\mathrm{a}}$

\begin{tabular}{|c|c|c|c|}
\hline & $\begin{array}{c}\text { Male } \\
\text { M (SD) }\end{array}$ & $\begin{array}{l}\text { Female } \\
\text { M (SD) }\end{array}$ & $\begin{array}{c}p \\
\text { value }^{\text {b }}\end{array}$ \\
\hline $\begin{array}{l}\text { If I did not have my smartphone with me, } \\
\text { I would feel anxious because I could not instantly communicate with my family and/or friends. }\end{array}$ & & & \\
\hline I would be worried because my family and/or friends could not reach me. & $4.2(1.8)$ & $4.8(1.8)$ & .03 \\
\hline I would feel nervous because I would not be able to receive text messages and calls. & $3.7(1.8)$ & $4.2(1.9)$ & .05 \\
\hline I would be anxious because I could not keep in touch with my family and/or friends. & $3.8(1.7)$ & $4.2(1.9)$ & .14 \\
\hline I would be nervous because I could not know if someone had tried to get a hold of me. & $3.8(1.8)$ & $4.5(1.8)$ & .02 \\
\hline I would feel anxious because my constant connection to my family and friends would $b$ & $3.2(1.6)$ & $3.6(1.8)$ & .1 \\
\hline Factor II: Losing connectedness (5 items) & $2.6(1.2)$ & $2.9(1.4)$ & .2 \\
\hline If I did not have my sma & & & \\
\hline I would be nervous because I would be discon & $1.8(1.2)$ & $2(1.2)$ & .16 \\
\hline $\begin{array}{l}\text { I would be uncomfortable because I could not stay up-to-date with social media and online } \\
\text { networks. }\end{array}$ & $2.6(1.6)$ & $2.9(1.8)$ & .41 \\
\hline $\begin{array}{l}\text { I would feel awkward because I could not check my notifications for updates from my connections } \\
\text { and online networks. }\end{array}$ & $2.8(1.9)$ & $2.9(1.7)$ & .65 \\
\hline I would feel anxious because I could not check my email messages. & $3.1(2)$ & $3.5(1.9)$ & 17 \\
\hline I would feel v & $2.9(1.9)$ & $3.2(1.8)$ & 29 \\
\hline Factor III: Not being able to access information ( 4 items) & $4.6(1.4)$ & $4.8(1.3)$ & .3 \\
\hline I would feel uncomfortable without constant access to informa & $4.5(1.7)$ & $4.6(1.7)$ & .53 \\
\hline I would be annoyed if I could not look information up on & $5.3(1.7)$ & $5.6(1.4)$ & 23 \\
\hline $\begin{array}{l}\text { Being unable to get the news (eg, happenings, weather, etc.) on my smartphone would make me } \\
\text { nervous. }\end{array}$ & $3.3(1.9)$ & $3.6(1.8)$ & .2 \\
\hline y smartphone and/or its capabilities when I wanted to do so. & $5.2(1.5)$ & $5.2(1.5)$ & .75 \\
\hline Factor IV: Giving up convenience (5 items) & $3.4(1.4)$ & $4.1(1.3)$ & .002 \\
\hline Running out of battery in & $3.4(2)$ & $3.7(1.8)$ & .23 \\
\hline If I were to run out of $\mathrm{cr}$ & $2.7(1.7)$ & $3.2(1.8)$ & .04 \\
\hline $\begin{array}{l}\text { If I did not have a data signal or could not connect to Wi-Fi, then I would constantly check to see if I } \\
\text { had a signal or could find a Wi-Fi network. }\end{array}$ & $3(1.9)$ & $3.5(1.9)$ & .07 \\
\hline If I could not use my smartphone, I would be afraid of getting stranded somewhere. & $3.3(1.9)$ & $4.9(1.6)$ & $<.001$ \\
\hline & $4.8(1.7)$ & $5(1.5)$ & .54 \\
\hline Overall Score & $3.5(1.2)$ & $4(1.2)$ & .02 \\
\hline
\end{tabular}

${ }^{a}$ NMP-Q consists of Likert-type items including: $1=$ Strongly disagree, $2=$ Disagree, $3=$ Somewhat disagree, $4=$ Neither agree nor disagree, $5=$ Somewhat agree, $6=$ Agree, and $7=$ Strongly Agree

${ }^{\mathrm{b}}$ One-way analysis of variance (ANOVA); $p<.05$ indicates statistical significance

more anxious over time. ${ }^{37}$ The nearly $20 \%$ of students in our study with severe nomophobia may have an overwhelming desire to stay in close contact with their smartphones, which could negatively affect learning. Research by Rosen and colleagues revealed that students averaged only six minutes on study tasks before switching to social networking apps or texts. ${ }^{38}$ Such powerful temptation to constantly switch tasks may prevent students from giving the sustained attention and thought necessary to fully comprehend complex material in pharmacy and other health professions curricula.

A second and more recent concern regarding student smartphone use is the potential negative effects the device has on mental health, an area that has been highlighted by ACPE standards as important for all pharmacy programs to address. ${ }^{33}$ One of the factors contributing to stress and anxiety that a growing number of researchers, psychologists, and mental health professionals attribute to smartphones is the inability (or unwillingness) to disconnect from digital communications. The constant need to check phones and apps (even during the middle of night) for missed calls, new texts, social media notifications, etc, keeps users in an "always on" mode, which prevents them from getting the mental and physical rest necessary for optimal cognitive and emotional functioning. ${ }^{39}$ One could reasonably expect that students with severe or even just moderate nomophobia would have compromised rest, which could ultimately lead to inordinate amounts of stress, anxiety, and/or other mental health issues. Not surprisingly, Sahin and colleagues' study of 504 college 


\section{American Journal of Pharmaceutical Education 2019; 83 (7) Article 7136.}

students found that sleep quality worsens with increasing levels of smartphone dependence. ${ }^{40}$ Even though the percentage of students with severe nomophobia in this study constituted a minority, that $18 \%$ signifies a high number of student pharmacists if they all presented with mental health concerns. Not only does that increase the difficulty of success for those students, it places a significant time investment on school personnel assigned to aid student mental health.

Another reason that pharmacy educators should address student overreliance and psychological dependence on smartphones is the potential negative effects for students as they enter experiential learning and graduates when they enter the workplace. Research has shown that while smartphones can be a very valuable tool when used appropriately, they can also become a distraction that potentially compromises patient health and safety. ${ }^{41,42} \mathrm{Be}-$ cause of this distraction, some preceptors, experiential sites, and employers may prohibit access to personal electronic devices. However, there is no reason to believe that student anxiety associated with smartphone separation will suddenly dissipate when they complete their training, graduate, and enter a residency program or seek employment.

Despite evidence suggesting that students with nomophobia may be more likely to experience negative mental health outcomes, it would be unwise to think that smartphones are the primary contributor. College student health and wellness concerns are complex with a variety of potential contributing factors including financial pressures, unstable family structures, previous mental health comorbidities, pressures to succeed, and many more personal and environmental issues. ${ }^{43}$ Research regarding the effects of smartphones on health and wellness is increasing, but it is still unknown as to whether smartphones themselves are causing the problems, whether the misuse is a form of coping, or whether there is a bidirectional effect of problematic smartphone use and psychological disorders. ${ }^{44}$ A significant amount of research is still needed to further comprehend the totality of the connections between digital technologies and wellness.

Although the results of this study indicated that nearly all students experience at least some degree of nomophobia, nomophobia and smartphones themselves are not necessarily the problem. The real issues may be the potential academic and personal well-being complications that arise because of the nomophobia and an unhealthy reliance on smartphones. This study provides a starting point for discussion, but further research is needed to understand the true extent and nuances of this contemporary issue.

If, as these results suggest, a considerable number of students suffer from nomophobia, the question becomes what actions, if any, institutions and educators should take to address the potential problems associated with it. As mentioned previously, more research is needed to discern the full extent and actual effects of nomophobia and smartphone dependence on mental health. Additional research questions could revolve around student understanding of the mental health issues associated with smartphones and their desire (or lack of) to limit reliance on digital devices and connections. Alongside that research, it may be time for colleges and schools to inform and educate students regarding the potential negative effects of smartphones so that they can self-regulate. ${ }^{45}$ Many may not realize that they have a problem, or that the problem even exists. Providing students with research-backed information, along with tools and suggestions on how to limit smartphone use, distractions, and psychological strain presumably caused by their digital devices would be a feasible intervention to investigate.

While the sample size of this study was similar to that of other studies evaluating nomophobia, our study population was small and isolated to student pharmacists at two universities. However, our study did include two pharmacy programs with different characteristics. One was a four-year traditional public institution, and the other was a three-year accelerated private institution. Larger studies with more diverse populations of health professions students should be conducted. While nomophobia research is relatively new, part of the name (ie, "-phobia") has negative implications. Also, the survey items contained key words like "anxious," "nervous," and "annoyed." Thus, social desirability bias may have caused students to underreport both their mobile phone usage and level of fear on the survey. ${ }^{46}$ Additionally, survey responses were selfreported, and therefore may have been inaccurate because of recall bias.

\section{CONCLUSION}

Nomophobia is a relatively new psychological phenomenon, and little is known about its potential impact or implications. To the authors' knowledge this was the first study characterizing nomophobia in student pharmacists. Nearly all of the student pharmacists in our study had NMP-Q scores consistent with some degree of nomophobia. Smartphones and other handheld internet devices have revolutionized the way people communicate, the way information is exchanged, and the way education is delivered. They are virtually indispensable for those in professional careers, but despite the tangible and significant benefits, these devices are not without potential downsides. As with other technological advances, overreliance and overuse can have unintended deleterious effects on other aspects of life. Educators must continue to 


\section{American Journal of Pharmaceutical Education 2019; 83 (7) Article 7136.}

study smartphone use and help students maximize the benefits of smartphones while avoiding the potential negative psychological consequences associated with their use.

\section{REFERENCES}

1. Pew Research Center. Mobile Fact Sheet. 2019; http://www. pewinternet.org/fact-sheet/mobile/. Accessed August 28, 2019.

2. Buchholz A, Perry B, Weiss LB, Cooley D. Smartphone use and perceptions among medical students and practicing physicians. J Mob Technol Med. 2016;5(1):27-32.

3. Smith A. Usage and attitudes toward smartphones. U.S. Smartphone Use in 2015. 2015; http:/www.pewinternet.org/2015/ 04/01/chapter-two-usage-and-attitudes-toward-smartphones/. Accessed August 28, 2019.

4. Cain J. It is time to confront student mental health issues associated with smartphones and social media. Am J Pharm Educ. 2018;82(7):Article 6862.

5. Elhai JD, Levine JC, Dvorak RD, Hall BJ. Fear of missing out, need for touch, anxiety and depression are related to problematic smartphone use. Comput Human Behav. 2016;63:509-516. 6. Harwood J, Dooley JJ, Scott AJ, Joiner R. Constantly connectedthe effects of smart-devices on mental health. Comput Human Behav. 2014;34:267-272.

7. Lemola S, Perkinson-Gloor N, Brand S, Dewald-Kaufmann JF, Grob A. Adolescents' electronic media use at night, sleep disturbance, and depressive symptoms in the smartphone age. J Youth Adolesc. 2015;44(2):405-418.

8. Samaha M, Hawi NS. Relationships among smartphone addiction, stress, academic performance, and satisfaction with life. Comput Human Behav. 2016;57:321-325.

9. Thomée S, Härenstam A, Hagberg M. Mobile phone use and stress, sleep disturbances, and symptoms of depression among young adults - a prospective cohort study. BMC Pub Health.

2011;11(1):66-76.

10. Alter A. Irresistible: The rise of addictive technology and the business of keeping us hooked. New York: Penguin; 2017.

11. Lewis P. Our minds can be hijacked: The tech insiders who fear a smartphone dystopia. 2017. https://www.theguardian.com/technology/ 2017/oct/05/smartphone-addiction-silicon-valley-dystopia. Accessed August 28, 2019.

12. Manjoo F. It's time for Apple to build a less addictive iPhone. 2018. https://www.nytimes.com/2018/01/17/technology/appleaddiction-iphone.html. Accessed August 28, 2019.

13. McKenzie L. Stop me before I text again. 2018. https:// www.insidehighered.com/news/2018/03/06/stanford-studentschallenge-apple-iphone-addiction. Accessed August 28, 2019. 14. De-Sola Gutiérrez J, Rodríguez de Fonseca F, Rubio G. Cellphone addiction: a review. Front Psychiatry. 2016;7:175.

15. King ALS, Valença AM, Silva ACO, Baczynski T, Carvalho MR, Nardi AE. Nomophobia: dependency on virtual environments or social phobia? Comput Human Behav. 2013;29(1):140-144.

16. Bragazzi NL, Del Puente G. A proposal for including nomophobia in the new DSM-V. Psychol Res Behav Manag. 2014;7:155.

17. Yildirim C, Correia A-P. Exploring the dimensions of nomophobia: development and validation of a self-reported questionnaire. Comput Human Behav. 2015;49:130-137.

18. Fjortoft N, Gettig J, Verdone M. Smartphones, memory, and pharmacy education. Am J Pharm Educ. 2018;82(3):Article 7054.
19. Dasgupta P, Bhattacherjee S, Dasgupta S, Roy JK, Mukherjee A, Biswas R. Nomophobic behaviors among smartphone using medical and engineering students in two colleges of West Bengal. Indian J Public Health. 2017;61(3):199-204.

20. Dixit S, Shukla H, Bhagwat A, et al. A study to evaluate mobile phone dependence among students of a medical college and associated hospital of central India. Indian J Community Med. 2010;35(2):339-341.

21. Farooqui IA, Pore P, Gothankar J. Nomophobia: an emerging issue in medical institutions? J Ment Health. 2017:1-4.

22. Madhusudan M, Sudarshan B, Sanjay T, Gopi A, Fernandes SD. Nomophobia and its determinants among the students of a medical college in Kerala. Int J Med Sci Public Health. 2017;6(6):1046-1050. 23. Ramudu R, Ramya Raj D, Reddy K, Ramana P. A study of assessment of mobile phone dependence among medical students in tertiary care teaching hospital. Indo Am J Pharm Res.

2015;5(8):2583-2587.

24. Sharma N, Sharma P, Sharma N, Wavare R. Rising concern of nomophobia amongst Indian medical students. Int J Res Med Sci. 2015;3(3):705-707.

25. Chandak P, Singh D, Faye A, et al. An exploratory study of nomophobia in post-graduate residents of a teaching hospital in Central India. Int J India Psychol. 2017;4(3):48-56.

26. Prasad M, Patthi B, Singla A, et al. Nomophobia: a crosssectional study to assess mobile phone usage among dental students. $J$ Clin Diagn Res. 2017;11(2):34-39.

27. Alahmari MS, Alfaifi AA, Alyami AH, et al. Prevalence and risk factors of nomophobia among undergraduate students of health sciences colleges at King Khalid University, Abha, Saudi Arabia. Int $J$ Med Res Prof. 2018;4(1):429-432.

28. Robert DF. Scale development: Theory and applications. 2nd ed. Thousand Oaks, CA: Sage Publication; 2003.

29. American Association of Colleges of Pharmacy. Academic Pharmacy's Vital Statistics. https://www.aacp.org/article/academicpharmacys-vital-statistics. Accessed August 28, 2019.

30. Tavakol M, Dennick R. Making sense of Cronbach alpha. Int J Med Educ. 2011;2:53.

31. Peeters MJ, Beltyukova SA, Martin BA. Educational testing and validity of conclusions in the scholarship of teaching and learning. Am J Pharm Educ. 2013;77(9):Article 186.

32. Cor MK. Measuring social science concepts in pharmacy education research: from definition to item analysis of self-report instruments. Curr Pharm Teach Learn. 2018;10(1):112-118. 33. Accreditation Council for Pharmacy Education. Accreditation Standards and Key Elements for the Professional Program in Pharmacy Leading to the Doctor of Pharmacy Degree ("Standards 2016"). 2015; https://www.acpe-accredit.org/pdf/Standards2016FINAL. pdf. Accessed August 28, 2019.

34. Hawi NS, Samaha M. To excel or not to excel: shtrong evidence on the adverse effect of smartphone addiction on academic performance. Comput Educ. 2016;98:81-89.

35. McCoy BR. Digital distractions in the classroom phase II: student classroom use of digital devices for non-class related purposes. J Media Educ. 2016;7(1):5-32.

36. Tossell CC, Kortum P, Shepard C, Rahmati A, Zhong L. You can lead a horse to water but you cannot make him learn: Smartphone use in higher education. Brit J Educ Technol. 2015;46(4):713-724.

37. Cheever NA, Rosen LD, Carrier LM, Chavez A. Out of sight is not out of mind: the impact of restricting wireless mobile device use on anxiety levels among low, moderate and high users. Comput Human Behav. 2014;37:290-297. 


\section{American Journal of Pharmaceutical Education 2019; 83 (7) Article 7136.}

38. Rosen LD, Carrier LM, Cheever NA. Facebook and texting made me do it: media-induced task-switching while studying. Comput Human Behav. 2013;29(3):948-958.

39. Sleek S. The psychological toll of the smartphone. 2014. https:// www.psychologicalscience.org/observer/the-psychological-toll-ofthe-smartphone. Accessed August 28, 2019.

40. Sahin S, Ozdemir K, Unsal A, Temiz N. Evaluation of mobile phone addiction level and sleep quality in university students. Pak J Med Sci. 2013;29(4):913.

41. Katz-Sidlow RJ, Ludwig A, Miller S, Sidlow R. Smartphone use during inpatient attending rounds: prevalence, patterns and potential for distraction. J Hosp Med. 2012;7(8):595-599.

42. Gill PS, Kamath A, Gill TS. Distraction: an assessment of smartphone usage in health care work settings. Risk Manag Healthc Policy. 2012;5:105.
43. Henriques G. What is causing the college student mental health crisis. Psychol Today 2014; https://www.psychologytoday.com/blog/ theory-knowledge/201402/what-is-causing-the-college-student-mentalhealth-crisis. Accessed August 28, 2019.

44. Elhai JD, Dvorak RD, Levine JC, Hall BJ. Problematic smartphone use: a conceptual overview and systematic review of relations with anxiety and depression psychopathology. $J$ Affect Disord. 2017;207:251-259.

45. Swar B, Hameed T. Fear of missing out, social media engagement, smartphone addiction and distraction: Moderating role of self-help mobile apps-based interventions in the youth. Paper presented at: International Joint Conference on Biomedical Engineering Systems and Technologies (BIOSTEC 2017) 2017. 46. Tourangeau R, Yan T. Sensitive questions in surveys. Psychol Bull. 2007;133(5):859-883. 